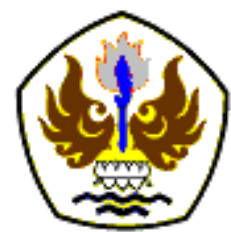

INFOMATEK

Volume 23 Nomor 1 Juni 2021

\title{
SIMULASI CFD ANALISA PENAMBAHAN TEMPERATUR PADA PEMBAKARAN OXY-FUEL BOILER DENGAN BAHAN BAKAR GAS ALAM
}

\author{
Ihsan Budiman*, Reza Setiawan, Oleh \\ Program Studi Teknik Mesin \\ Fakultas Teknik - Universitas Singaperbangsa Karawang
}

\begin{abstract}
Abstrak: Sumber terbesar yang menghasilkan emisi Karbon Dioksida $\left(\mathrm{CO}_{2}\right)$ dipercaya berasal dari pembangkit daya yang menggunakan bahan bakar fosil. Efek rumah kaca dan pemanasan global, merupakan dampak yang dihasilkan oleh emisi $\mathrm{CO}_{2}$. Berikut adalah beberapa teknologi yang berfungsi untuk menangkap $\mathrm{CO}_{2}$ pada industri utilitas. Dalam hal ini teknologi penangkapan gas karbon diantaranya pre-combustion, post-combustion, dan oxy-fuel combustion. Hanya saja ada keterbatasan pengalaman dalam penggunaan oxy-fuel dalam pembakaran gas alam dan batu bara pada dunia industri, untuk itu digunakan metode numerik seperti Computational Fluid Dynamics (CFD) dalam membantu menyelesaikan tantangan teknis seperti perpindahan panas didalam Boiler. Berdasarkan hasil simulasi didapat temperatur maksimum pada pembakaran konvensional sebesar 1860 celcius sementara pada pembakaran oxy-fuel sebesar 2840 celcius. Dengan ini maka dapat disimpulkan pembakaran oxy-fuel selain mengurangi emisi gas $\mathrm{CO}_{2}$ juga menghasilkan temperatur yang lebih tinggi untuk dimanfaatkan dalam pembuatan steam pada Boiler.
\end{abstract}

Kata kunci: Boiler, Computational Fluid Dynamic,Oxy-Fuel, Gas Alam

\section{PENDAHULUAN}

Sumber terbesar yang menghasilkan emisi Karbon Dioksida $\left(\mathrm{CO}_{2}\right)$ dipercaya berasal dari pembangkit daya yang menggunakan bahan bakar fosil. Efek rumah kaca dan pemanasan global, merupakan dampak yang dihasilkan oleh emisi $\mathrm{CO}_{2}$. Dilaporkan oleh International Energy Agency, penggunaan bahan bakar fosil secara global mencapai $80 \%$ dari total kebutuhan energi. Sementara $40 \%$ penyebab

\footnotetext{
*) 1610631150057@student.unsika.ac.id
}

Pertama diterima: 5 Desember 2020

Direvisi: 9 Desember 2020

Disetujui untuk publikasi: 17 Mei 2021 emisi $\mathrm{CO}_{2}$ dihasilkan oleh pembangkit listrik, yang mana $30 \%$ nya menggunakan bahan bakar fosil. Berikut adalah beberapa teknologi yang berfungsi untuk menangkap $\mathrm{CO}_{2}$ pada industri utilitas. Dalam hal ini teknologi penangkapan gas karbon diantaranya precombustion, post-combustion, dan oxy-fuel combustion. (Ibrahim B. Mansir [1]).

Oxy fuel combustion merupakan teknologi carbon capture and storage (CCS) yang muncul untuk sistem pembangkit listrik dimana bahan bakar tidak dicampur dengan udara, 
melainkan dengan oksigen dan campuran recirculate flue gas (RFG). Gas buang yang muncul nantinya akan mengandung $\mathrm{CO}_{2}$ dan uap air yang setelah pemurnian dapat dikompresi dan dimanfaatkan, misalnya untuk meningkatkan perolehan minyak. Pada akhirnya, mengkombinasikan teknologi oxy fuel dengan pembakaran biomasa dapat mengurangi emisi gas buang dengan menghilangkan 800 milliar ton $\mathrm{CO}_{2}$ dari atmosfer setiap tahunnya. Hanya saja ada keterbatasan pengalaman dalam penggunaan oxy fuel dalam pembakaran gas alam dan batu bara pada dunia indsutri, untuk itu digunakan metode numerik seperti Computational Fluid Dynamics (CFD) dalam membantu menyelesaikan tantangan teknis seperti perpindahan panas didalam boiler. (A. Pranzitelli [2]).

CFD merupakan alat desain yang dapat digunakan untuk mempelajari boiler, seperti bidang aliran pada boiler, temperatur dan distribusi bahan kimia yang dimana akan sulit apabila dilakukan eksperimen secara langsung. CFD untuk pembakaran sudah pernah diaplikasikan pada pembakaran udarabatu bara, udara-gas alam, dan pembakaran campuran udara-gas alam-batu bara. Maka dari itu CFD digunakan untuk mempelajari efek pepindahan panas seperti konduksi, konveksi dan radiasi dalam proses pembakaran gas alam dan batu bara. [2].
Tujuan dari simulasi ini adalah membandingkan temperatur pembakaran pada boiler yang menggunakan udara pembakaran biasa dengan pembakaran oxyfuel.

\section{METODOLOGI}

\subsection{Alur Penelitian}

Sebelum memulai penelitian kita perlu mempersiapkan data-data yang dibutuhkan dalam simulasi seperti data geometri boiler, laju aliran massa bahan bakar, dan laju aliran masa udara pembakaran. Selanjutnya data yang telah dikumpulkan diolah menggunakan software CFD (Computational Fluid Dynamics). Pada software CFD data-data tersebut diolah dan diatur sehingga menyerupai kondisi operasional boiler yang sebenarnya seperti tipe aliran (laminar/turbulen), jenis bahan bakar dan kandungannya, kandungan udara pembakaran yang mana pada pembakaran konvensional kandungan oksigen sebesar $21 \%$ sementara pada pembakaran oxy-fuel, oksigen pada udara pembakarannya sebesar 95\% hingga 100\%. Selanjutnya dilakukan verifikasi data antara data desain temperatur pembakaran dengan data hasil simulasi CFD untuk melihat seberapa besar eror yang didapat. Selanjutnya didapat hasil dari temperatur pembakaran antara udara konvensional dan pembakaran oxy-fuel sehingga dapat dianalisa perbedaan diantara 
keduanya. Diagram alir penelitian ditunjukkan seperti pada Gambar 1.

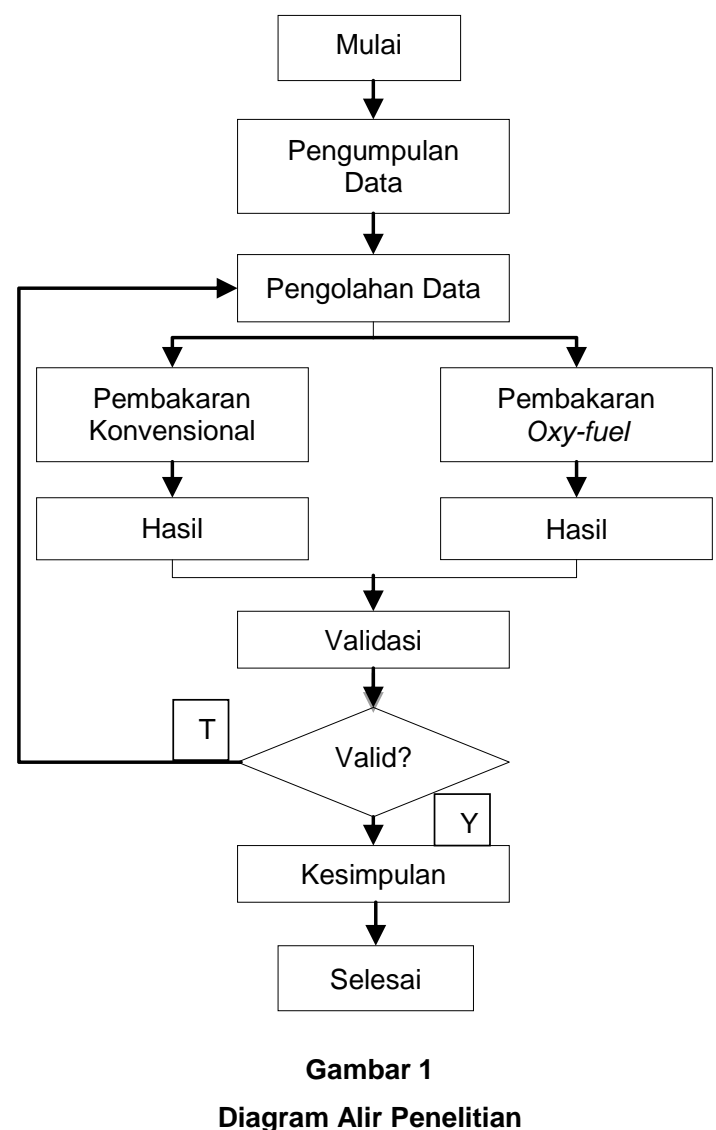

\subsection{Tahapan CFD}

Software yang digunakan pada simulasi ini adalah Ansys Fluent 17.0. Terdapat beberapa tahapan untuk mendapatkan hasil simulasi diantaranya:

a. Pre-processing, yakni mendefinisikan geometri, kondisi batas, variabel yang akan dimasukkan, fenomena fisik seperti jenis aliran (laminar/turbulen), dan lain-lain.

b. Processing, hal yang perlu dipertimbangkan dalam tahap processing adalah kualitas perhitungan dan lama waktu perhitungan.

c. Post-processing, pada tahap ini, hasil simulasi dapat ditampilkan dalam bentuk 1D berupa plot atau diagram, bentuk 2D berupa kontur, dan bentuk 3D berupa animasi.

d. Verifikasi dan Validasi, pada tahap ini dapat dilakukan dengan berbagai cara diantaranya pemeriksaan kode CFD, memeriksa konvergensi residu hasil, membandingkan hasil simulasi dengan data desain, dan lain-lain.

Gambar 2 memperlihatkan diagram alir dari CFD.

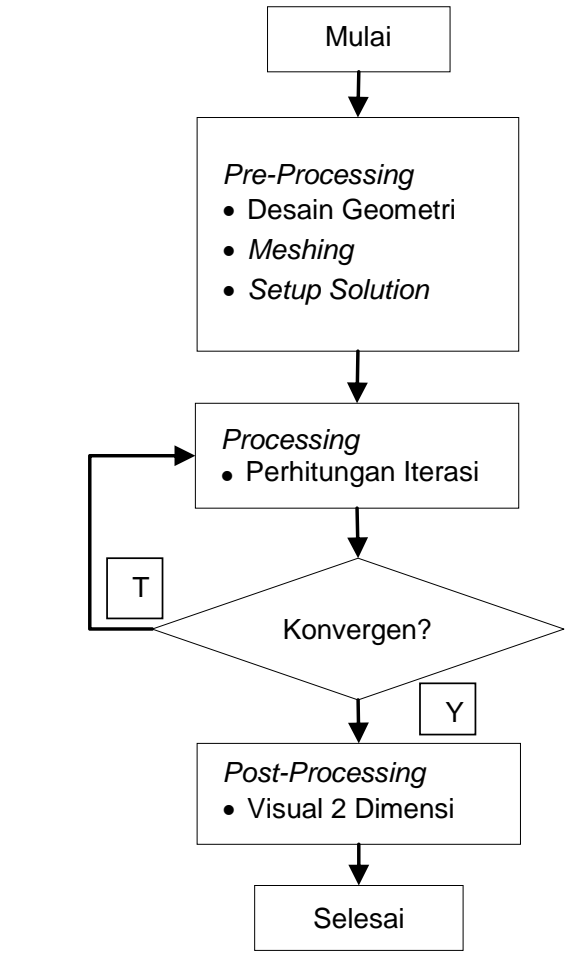

Gambar 2

Diagram Alir CFD 


\section{ANALISIS DAN PEMBAHASAN}

\subsection{Desain Boiler}

Spesifikasi boiler yang akan digunakan sebagai berikut sebagai berikut:

a. Jenis Boiler : Package Boiler

b. Tipe Boiler : Water Tube Wall

c. Dimensi Utama $(p \times \mid \times t): 10.698 \times 5156 \times$ $6486 \mathrm{~mm}$

d. Jumlah Burner : 2 set

Hasil desain geometri boiler ditunjukkan oleh Gambar 3.

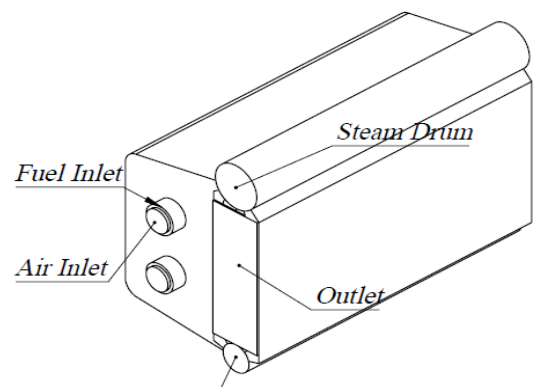

Water Drum

\section{Gambar 3}

Desain Packaged Boiler untuk simulasi CFD

\subsection{Setup Solution}

Setup solution pada simulasi ini ditunjukkan pada tabel berikut.

Tabel 1

Setup solution

\begin{tabular}{ll}
\hline Model & Keterangan \\
\hline Energy Equation & On \\
\hline Viscous (Turbulen) & K-E, RNG \\
\hline Radiation & On \\
\hline Species & Species Transport \\
\hline
\end{tabular}

Energy equation berfungsi untuk menggunakan algoritma CFD dalam perhitungan perpindahan panas pada simulasi. Sementara K- $\mathrm{E}$ Renormalization Group, berfungsi untuk perhitungan pada jenis aliran turbulen dan berpusar. Species Transport, untuk menentukan jenis bahan bakar dan reaksi kimia yang terjadi.

\subsection{Kondisi Batas}

Kondisi batas pada simulasi ditentukan berdasarkan kondisi operasional boiler sebenarnya yang ditunjukkan oleh tabel sebagai berikut.

Tabel 2

Data Operasional

\begin{tabular}{ccccc}
\hline No & Lokasi & $\begin{array}{c}\text { Tekanan } \\
(\mathrm{Pa})\end{array}$ & $\begin{array}{c}\text { Mass } \\
\text { Flow Rate } \\
(\mathrm{Kg} / \mathbf{s})\end{array}$ & $\begin{array}{c}\text { Temperatur } \\
\text { (Celcius) }\end{array}$ \\
\hline 1 & $\begin{array}{c}\text { Inlet } \\
\text { Udara }\end{array}$ & 4952,3582 & 31,19722 & 35 \\
\hline & Inlet & & & \\
2 & Bahan & 142196,4 & 1,755833 & - \\
& Bakar & & & \\
\hline 3 & Outlet & 677,640 & 32,9530 & 727,9 \\
\hline
\end{tabular}

\subsection{Hasil Simulasi Pembakaran} konvensional

Hasil dari simulasi pada pembakaran menggunakan udara konvensional sebagai berikut.

Tabel 3

Persentase Error Pada Hasil Simulasi

\begin{tabular}{ccc}
\hline $\begin{array}{c}\text { Data Desain } \\
\text { (Celcius) }\end{array}$ & $\begin{array}{c}\text { Hasil Simulasi } \\
\text { (Celcius) }\end{array}$ & Error \\
\hline 1820 & 1860 & $2,15 \%$ \\
\hline
\end{tabular}


Untuk menampilkan kontur distribusi temperatur pada hasil simulasi, dibuatkan plane sebagai berikut.

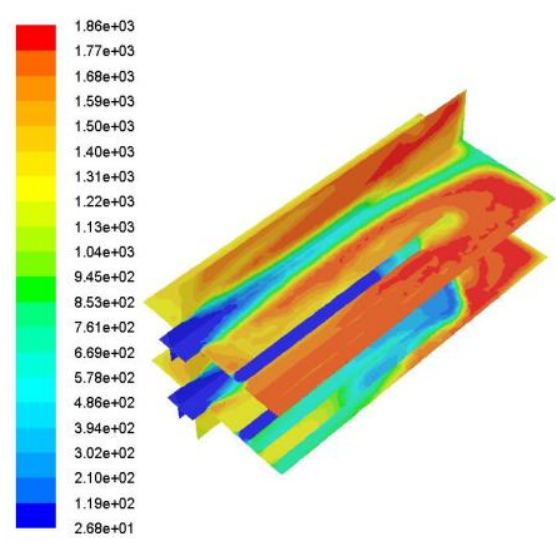

Gambar 4

Kontur Distribusi Temperatur Pembakaran

Konvensional

Pada pembakaran udara konvensional, nilai heat reaction maksimum berdasarkan hasil simulasi didapat sebesar 14900 watt yang ditunjukkan pada kontur sebagai berikut.

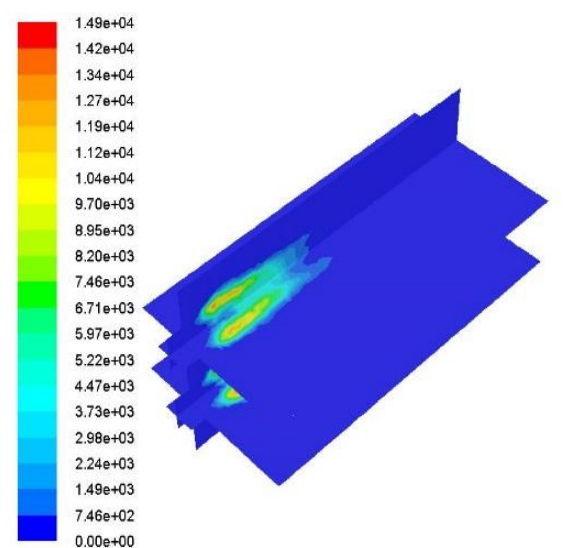

Gambar 5

Kontur Heat Reaction Pada Pembakaran

Konvensional

\subsection{Hasil Simulasi Pembakaran Oxy-fuel}

Perbandingan temperatur antara pembakaran konvensional dan pembakaran oxy-fuel ditunjukkan pada tabel berikut.

Tabel 4

Penambahan Temperatur

\begin{tabular}{ccc}
\hline $\begin{array}{c}\text { Konvensional } \\
\text { (Celcius) }\end{array}$ & $\begin{array}{c}\text { Oxy-fuel } \\
\text { (Celcius) }\end{array}$ & $\begin{array}{c}\text { Persentase } \\
\text { Penambahan }\end{array}$ \\
\hline 1860 & 2840 & $34,26 \%$ \\
\hline
\end{tabular}

Kontur distribusi temperatur pada pembakaran oxy-fuel ditunjukkan oleh gambar berikut.
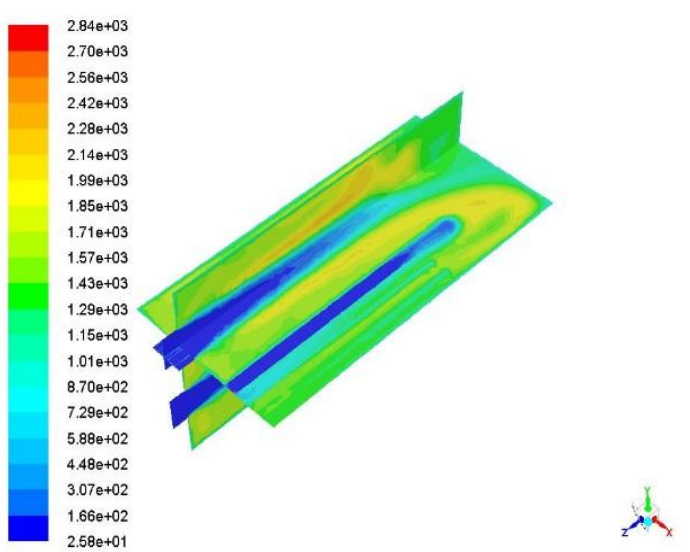

Gambar 6

Kontur Distribusi Temperatur Pembakaran Oxy-fuel

Perbandingan heat reaction pada pembakaran konvensional dan pembakaran oxy-fuel ditunjukkan pada tabel berikut.

Tabel 5

Perbandingan Heat Reaction

\begin{tabular}{ccc}
\hline $\begin{array}{c}\text { Konvensional } \\
\text { (Watt) }\end{array}$ & $\begin{array}{c}\text { Oxy-fuel } \\
\text { (Watt) }\end{array}$ & $\begin{array}{c}\text { Persentase } \\
\text { Penambahan }\end{array}$ \\
\hline 14900 & 16100 & $7,45 \%$
\end{tabular}


Kontur heat reaction pada pembakaran oxyfuel ditunjukkan pada gambar berikut.

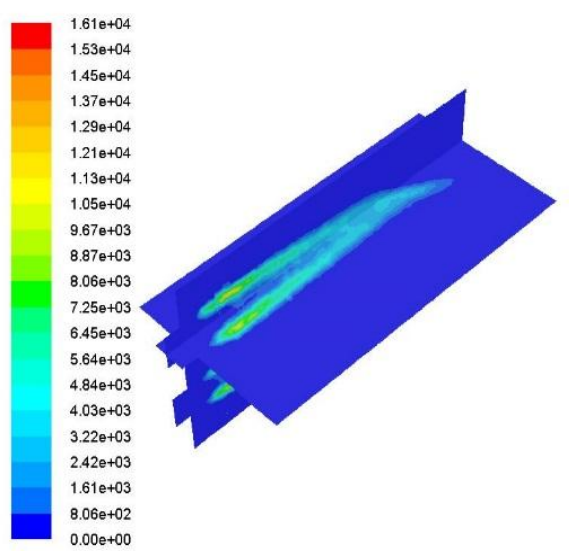

Gambar 7

Kontur Heat Reaction Pada Pembakaran Oxy-fuel

\section{KESIMPULAN}

Kesimpulan yang dapat diambil dari hasil simulasi diatas sebagai berikut:

1. Pada simulasi pembakaran menggunakan udara biasa, temperatur maksimal sebesar 1860 Celcius, sementara pada data desain temperatur pembakaran sebesar 1820 Celcius. Dari hasil tersebut, didapat nilai error sebesar $2,15 \%$.

2. Untuk pembakaran oxy-fuel, nilai temperatur maksimum sebesar 2840 Celcius. Dengan begitu pengaplikasian oxy-fuel pada pembakaran didalam Boiler selain mengurangi emisi $\mathrm{CO}_{2}$ juga dapat meningkatkan temperatur temperatur pembakaran sebesar $34,26 \%$.

3. Nilai heat reaction pada pembakaran menggunakan udara konvensional sebesar 14900 watt dan pada pembakaran oxy-fuel sebesar 16100. Dengan begitu terjadi peningkatan sebesar $7,45 \%$.

\section{DAFTAR PUSTAKA}

[1] Ibrahim B. Mansir., Rached BenMansour., Mohamed A. Habib., " Oxy-fuel Combustion in a Two-pass Oxygen Transport Reactor for Fire Tube Boiler Application, 2018.

[2] A. Pranzitelli., S. Black., J. Szuhanszki., L. Ma., P.J. Stranger., D.B. Ingham., M. Pourkashanian., " Effect of Firing Coal and Biomass Under Oxy-fuel Condition in a Power Plant Boiler Using CFD Modelling, 2013. 